\title{
State of the dentoalveolar system in children from mothers with gestational hypertension
}

\author{
L. A. Saidova ${ }^{1}$, N. N. Khabibova ${ }^{2}$ \\ ${ }^{1,2}$ Bukhara state medical Institute, \\ Uzbekistan
}

\begin{abstract}
Development of diagnostic and practical criteria for arterial hypertension and complications in children from mothers with gestational hypertension against the background of the use of calcium channel inhibitors.

In 2018, new European recommendations on cardiovascular diseases during pregnancy and European recommendations on arterial hypertension were published, which have special sections on hypertension in pregnant women. The recommendations draw attention to the fact that hypertensive disorders during pregnancy are the most common medical complications affecting 5-10\% of pregnancies worldwide, and remain the main cause of maternal, fetal and neonatal morbidity and mortality. The fetus is at high risk of intrauterine growth retardation (25\% of cases in preeclampsia (PE), prematurity (27\% of cases in PE), and intrauterine death (4\% of cases in PE). Women with a high or moderate risk of developing PE are recommended to take 100-150 mg of acetylsalicylic acid daily between 12 and 36-37 weeks of pregnancy (recommendation class 1, evidence level A). In addition, to prevent PE in women with low calcium intake $(<600 \mathrm{mg} / \mathrm{day})$, it is recommended to introduce calcium into the diet (1.5-2 g/day, orally), which should begin after the first visit to the women's consultation. The recommendations specifically draw attention to the fact that vitamins $\mathrm{C}$ and $\mathrm{E}$ do not reduce the risk of PE.
\end{abstract}

Key words: diagnostic and practical criteria , arterial hypertension, medical complications, calcium.

\section{Introduction}

On the one hand, dental pathology itself is a factor that violates the quality of life during pregnancy. on the other hand, it is known that the presence of periodontal pathology is a risk factor for severe pregnancy complications [Canakci V., Ingec M., 2004], such as preeclampsia and eclampsia, gestosis of the second half of pregnancy. According to N. J. Thomas (2008), more than 56\% of pregnant women over 30 years of age have pathological changes in the periodontium. It is known that in addition to bacterial factors, a lot of common factors play a role in the pathogenesis of periodontal pathology, including and the presence of somatic pathology. According to who (2003), hypertensive syndrome occurs in 4-10\% of pregnant women, and accounts for 20$30 \%$ of the structure of maternal mortality. Serious complications of hypertension during pregnancy are gestosis of the second half of pregnancy, preeclampsia and eclampsia. In light of the increased risk of these complications in women with chronic periodontitis, and data on complications of arterial hypertension during pregnancy, we decided to study the issue of dental monitoring of pregnant women with gestational and chronic arterial hypertension. In 1982, J. cockbum And co-authors provided data on a study examining the effect of antihypertensive therapy with methyldopa during pregnancy on the growth and development of children born. This study deserves special attention due to the very long follow-up period of 7.5 years. There are no other similar studies on hypertension in pregnant women. The authors examined 195 (97.5\%) children of women with hypertension during pregnancy at birth and 7.5 years later. Women who received methyldopa made up the main group, and those who did not receive it - the control group. It was found that the frequency of problems with health, physical or mental development, vision, hearing and behavior was the same in children of women from the main and control groups. Meanwhile, to date, we have not found any studies of the state of the dental system in children aged 7-8 years from mothers with hypertension who received calcium antagonists in the literature.

Scientific data that meet the criteria of evidence-based medicine for the treatment of hypertension during pregnancy is extremely insufficient. The only study on the treatment of hypertension during pregnancy with adequate follow-up for children (up to 7.5 years) was published 40 years ago. in this study, methyldopa was used for the treatment of hypertension in pregnant women (in Russia, this drug is Dopegit). First of all, the obvious fact that although the goal of hypertension treatment is to reduce the risk for the mother, the selected antihypertensive drugs should be safe for the fetus is once again emphasized. In addition, it is recommended to 
prescribe beta blockers (most data are provided for labetalol) (recommendation class 1, evidence level C) or calcium antagonists (most data are provided for nifedipine) (recommendation class 1, evidence level C). Betablockers are less effective than calcium antagonists and can cause fetal bradycardia, growth retardation, and hypoglycemia; therefore, the drug and its dosage should be carefully selected. For severe hypertension, medication with methyldopa or nifedipine(oral) or labetalol (intravenous) is recommended. recommendation class 1 , level of evidence.

\section{Purpose of research}

study of the features of the dental system in children from mothers with gestational hypertension against the background of the use of calcium channel antagonists and development of pathogenetically justified recommendations for their prevention and treatment.

Research objectives:

1. to Study the prevalence and structure of diseases of the dental system in children 6-8 years of age from mothers with gestational hypertension against the background of the use of calcium antagonists.

2. to Identify the characteristic features of microbiocenosis and the local protective system of the oral cavity in this group of children.

3. To study the hormonal status of saliva and blood in this population of children.

4. based on the conducted research, to offer pathogenetically sound recommendations for the diagnosis and prevention of detected violations of the dental system in children.

5. develop an algorithm for the diagnosis and prevention of prevention and progression of pathological processes in the dental system in children.

\section{Object of research}

Pregnant women with arterial hypertension will be studied on the basis of a retrospective study of stationary chart data for the last year.

Method of research. During scientific research, a set of methods will be used depending on the tasks: collection and study of complaints, collection and analysis of anamnesis, oral examination, palpation of periodontal and SOPR, palpation of lymph nodes and salivary glands, use of samples for periodontal examination (CPITN and PMA indices), oral hygiene (OHI-S and Fedorova-Volodkina indices), x-ray and laboratory studies. At the end of the work, it is planned to develop and approve protocols for diagnostics, differential diagnostics, prevention and treatment of children aged 6 - 8 years with pathology of the maxillary system. The effectiveness of protocols as quality criteria will be established. The use of protocols in practice will help to improve the quality and effectiveness of diagnostic and therapeutic work, reduce complications, significantly improve the function of organs and the hygienic condition of the oral cavity.

\section{REFERENCES}

1. Abakumov S. A. Neurocirculatory dystonia (lecture)./ S. A. Abakumov // Doctor.- 1997. no. 2. - P. 6-8.

2. Abramov A. A. Analgesia in patients with hypotonic form of neurocirculatory dystonia in outpatient dental interventions: autoref. Diss. candidate of medical Sciences. Stavropol-1996.-39 p.

3. Avtandilov A. G. The value of information characteristics of echocardiographic parameters in the diagnosis of neurocirculatory dystonia and hypertension in adolescence. / A. G. Avtandilov // Cardiology.1998.- vol. 38, No. 6. P. 55-58.

4. Ageeva L. sh. the Nature of the course of chronic periodontal diseases in schoolchildren with different States of adaptation of the body. /L. Sh. Ageeva // Kazan, state med. Univ. Kazan.- 1999.-P. - 17.

5. Admakin O. I. Dental morbidity of the population in various climatic zones of Russia//Abstract. Diss.kand. med. nauk.-M.-1998.-28 p.

6. Akulovich A.V. periodontal pathology./ A.V. Akulovich // World of medicine.-1999. No. 5 P. 3-6.

7. Alimova G. G. Morphological bases of blood flow regulation in the microcirculatory bed/G. G. 
Alimova//Regional blood circulation and microcirculation. 2003. - No. 4(8) - P. 80-84.

8. Alimsky A.V. indicators of dental caries and dental System abnormalities in children with cleft lip and palate./ A.V. Alimsky, F. M. Abdulakhum// Stomatology of children's age and prevention.- 2007.-No. 1.P. 24-25.

9. Arabidze G. G., Arabidze, Gr.G. Hypertensive crises: classification, diagnosis of complications, treatment /F. F. Arabidze, Gr.G. Arabidze// Cardiology:- 1999!- Vol. 39; No. 10-C186-91.

10. Arutyunov S. D. New opportunities for prevention and treatment; initial forms of caries in young children./ S. D. Arutyunov;. MPZ-Sverdlov, M. V. Kosmicheskaya// Dentistry, children's age; and prevention;-2007.-No. 3:-P. 23-26.

11. barer G. M. Clinical and immunological indicators for herpetic stomatitis of the oral mucosa in pregnant women / F. M. barer, L;E. Murashko, T. A. Rastegina//New in dentistry.- 2004. №5 (121). - Pp. 68-70.

12. barer, G. M. application of Kalgan tincture for correction of vascular disorders in periodontitis on the background of diabetes mellitus in the experiment/ G. M. barer, A. I. Volozhin, Kh. T. Osmanova, V. V. Gomonov // Department. 2006. - no. 4.- P. 34-38.

13. Bebikhov, D. V. Nemendelevskoe inheritance of arterial* hypertension: repetitive DNA sequences as candidates for the role .genomic determinants / D'.To> Babichev, T. A. Nikonenko, A. Y. Postnov, Y. V. Postnov, // Cardiology. 2001. - No. 6. - P. 34-41.

14. Bezrukova I. V. rapidly Progressing periodontitis: Etiology. Clinic. Treatment: Autoref. Diss.kand. med. nauk. -M. - 2000. 26 p.

15. Belova N. A. state of hard tooth tissues and periodontal tissues in patients with primary arterial hypertension./ N. A. Belova; L. E. Leonova, T. L. Sirotina// Scientific session of PGMA: TEZ. Dokl.Perm.- 1997.-P. 356.

16. Belova, V. V. Clinical and functional characteristics of the initial manifestations of circulatory insufficiency of the brain in young people with idiopathic arterial hypotension: autoref. Diss.kand.med.nauk / V. V. Belova M., 2005.- 21s.

17. Belogortseva, E. A. state of metabolism in children with arterial Hypo - and hypertension: autoref. Diss.kand.med.nauk / E. A. Belogortseva. — M., 2004: 20 p.

18. Belozerov, Yu. M. New achievements in pharmacotherapy for cardiovascular diseases in children /Yu. M. Belozerov, M. A. Shkolnikova, I. V. Leontieva, V. V. bereznitskaya // Pediatrics. 1995. - No. 4. - P. 128135.

19. Belokopytova, V. V. criteria for assessing the degree of microcirculatory disorders in periodontal diseases / In:V. Belokopytova // Central research Institute of stomat. MZ RF. M. - 2002.- P. - 26.

20. Berezovskaya; L. V. Chronic' arterial hypotension' in young women with reproductive system dysfunction: autoref. Diss. kand. med. nauk / L. V. Berezovskaya. M., 2005. - 20 p.

21. Bobokalonova, Z. M. Clinical and functional characteristics of changes in the' mucosa* of the oral cavity and periodontal cavity in hypertensive" diseases: abstract: Diss.kand. med. nauk / Z. M. Bobokalonova. M., 2004. - 19 p.

22. Bova, A. A., Trisvetova, E. L. the role of vasoactive endothelial factors in the development of arterial hypertension/ A. A. Bova, E. L. Trisvetova // Cardiology. 2001. - No. 7.- Pp. 57-59.

23. Borisenko L. G. method "Cardiogram" in the clinical prognosis of dental caries*:/L. G. Borisenko, S. M. Tikhonova// Clinical dentistry. - 2004.-No. 1. P. 20-24.

24. Borichevskaya, L. V. change in the state,microcirculatory bed In periodontitis against the background of the development of convulsive syndrome /L. V. Borichevskaya, G. M. barer, P. N. Aleksandrov // Mat. Everything is fine. scientific Conf. "Microcirculation in clinical practice" M. - 2004. - P. 21.

25. Borovsky E. V. Terminology and classification of dental caries and its complications. /E. V. Borovsky// Clinical dentistry.-2004.-No. 1.-P. 6-10. 
26. Borodina, I. I. features of hemodynamics of periodontal tissues in individuals with a small vestibule of the oral cavity / I. I.: Borodina, G. H. ermolyev // Russian stomatological journal. — 2004. No. 1. S. 19-21.

27. Borodulina, E. V. Estimation of reserve possibilities of the kallikrein-kinin system of the blood of healthy people /E. In: Borodulin // Klinicheskaya laboratory diagnostics - 1998.- No. 5.- S. 9-10.

28. Borodulina, T. A. hypotension and its prognostic significance in the development of cerebrovascular disorders in adolescents: Avtoref. Diss. Cand. med. Sciences / T. A. Borodulina; Mi, 2004. - 21 S.

29. Borodulina, T. A. Cerebral dyscirculations in adolescents suffering from arterial hypotension / T. A. Borodulina // Russian journal of Pediatrics, 2005, no. 2, pp. 15-16.

30. Brin V. B. influence of heavy metal salts on systemic hemodynamics and noradrenaline reactivity in rats /V. B. Brin, O. T. Kabisov//Russian Physiol. journal im; I;M:Oechenova.-2004.-Vol. 90:-No. 8.-P. 267268.

31. Brin V. B. human Physiology in diagrams and tables./ V. B. Brin // Second edition. Feniks, Rostov:n/A:1999.-348 p.

32. Bubnov Yu. I. Family arterial: hypotension./ Yu. I. Bubnov, F. F. Arabidze, A. A. Popov// Cardiology.1997. No. 1. - G. 4 - 8.

33. Bulkina, N. V. Some mechanisms of occurrence and progression: inflammatory periodontal diseases in patients with combined pathology of the gastrointestinal tract / N. V. Bulkina, M. A. Osadchuk// Dentistry. -2007.-No. 1.-Pp. 24-26.

34. Bulkina, N. V. violation of antithrombogenic properties of the vascular wall as a factor in the pathogenesis of rapidly progressive periodontitis / N. V. Bulkina, E. V. Ponukalina, I. N. Karpenko // Dentistry. 2007. No. 1. - Pp. 15-19. 